\title{
Catabolic effect of dexamethasone in the preterm baby
}

\author{
K G Brownlee, P C Ng, M J Henderson, M Smith, J H Green, P R F Dear
}

\begin{abstract}
Most babies treated with dexamethasone for bronchopulmonary dysplasia exhibit an appreciable rise in the blood urea concentration, from a mean of $2.3 \mathrm{mmol} / 1$ before steroid to a mean of $7 \cdot 1 \mathrm{mmol} / \mathrm{l}$ after. In order to discover whether this was primarily the result of increased protein catabolism, nitrogen balance studies before and after the start of dexamethasone were performed and a mean deficit in nitrogen retention of $158 \mathrm{mg} / \mathrm{kg} / 24$ hours was found. Similarly the urinary 3methylhistidine (3MH):creatinine ratio before and after the commencement of dexamethasone treatment in a group of preterm babies was measured. It was found that there was a substantial increase in $\mathbf{3 M H}$ excretion after dexamethasone: from a mean $3 \mathrm{MH}$ :creatinine ratio of 46 in the week before steroids to a mean ratio of 77 in the week after. As $3 \mathrm{MH}$ emanates almost exclusively from the breakdown of actin in skeletal muscle cells, this finding implies the loss of muscle tissue. It was also found that the babies were in less positive nitrogen balance after dexamethasone, to a degree which is significant relative to their protein reserves. The long term consequences of a period of increased catabolism are not yet known but the authors suggest caution in the use of dexamethasone, at least in babies with milder degrees of bronchopulmonary dysplasia in whom the ratio of benefit to risk may be less favourable.
\end{abstract}

Corticosteroid treatment is now an established part of the management of bronchopulmonary dysplasia. While large, multicentre, research studies will hopefully continue to define the precise indications for the use of steroids, numerous informal 'studies' are being conducted in individual units. The decision to use steroids will be based on a clinician's perception of the risk:benefit ratio in an individual case. As it is likely that there will be a move towards using corticosteroids earlier in the course of the disease and in less severe cases (as seems an inevitable phase in the evolution of any effective drug treatment) more information about the risks must be sought so that the risk:benefit ratio can be evaluated as accurately as possible.

A striking phenomenon that we have observed in almost all dexamethasone treated preterm babies is a sharp rise in the blood urea concentration. This usually begins within 48 hours of starting the drug and lasts for a week or so. As dexamethasone is well known to increase protein catabolism in adults, ${ }^{1}$ we thought that this was the most likely explanation for the observation. As any increase in protein catabolism in a sick preterm baby with poor nutritional reserves and limited renal function is potentially very harmful, we have investigated the effect further.

In order to see if there was evidence of increased protein catabolism we performed nitrogen balances before and during dexamethasone treatment of 11 infants. In order to see if there was evidence of catabolism of endogenous structural protein, as distinct from dietary protein, we also studied the urinary excretion of 3-methylhistidine (3MH). $3 \mathrm{MH}$ results from the methylation of the amino acid histidine and its sole source in the newborn infant is the protein actin. ${ }^{23}$ The vast majority of actin is to be found within skeletal muscle (the $3 \mathrm{MH}$ concentration in skeletal muscle being at least 10 times that in other tissues), but small amounts are found in other cell types. $3 \mathrm{MH}$ is released when actin is broken down. It is not metabolised in man and is fully excreted in the urine. As, in the absence of meat from the diet, creatinine is excreted in proportion to the skeletal muscle mass, the urinary $3 \mathrm{MH}$ : creatinine ratio should be proportional to the fractional degradation rate of myofibrillar protein. The $3 \mathrm{MH}$ :creatinine ratio has been found to correlate well with nitrogen balance in preterm infants, ${ }^{4}$ and several authors have used $3 \mathrm{MH}$ excretion to quantify protein turnover and muscle breakdown in adults and neonates, in relation to nutritional state, surgery, and trauma ${ }^{5-7}$ In animals, $3 \mathrm{MH}$ excretion has been used to demonstrate a rise in protein catabolism after dexamethasone treatment. ${ }^{8}$

\section{Patients and methods}

Four groups of babies were investigated.

GROUP 1

In this group of 11 babies full nitrogen balance studies were performed before and after the start of steroids. Boys were selected because of the relative ease of collecting complete urine specimens. Twenty four hour balance studies were conducted immediately before the start of steroids and again on the third day of treatment. All of the babies were parenterally fed and none produced any stools during the balance studies.

GROUP 2

In order to examine the day to day variation in the $3 \mathrm{MH}$ :creatinine ratio, and the reproduci- 
bility of the measurement method, we obtained urine specimens from 10 preterm babies who were healthy and growing normally on full milk feeds. Five specimens were collected from each baby over a two week period.

\section{GROUP 3}

This group comprises 34 babies treated with dexamethasone for bronchopulmonary dysplasia during a three year period (1987-9). Each had received a three week course of dexamethasone: $0.6 \mathrm{mg} / \mathrm{kg} /$ day in the first week, $0.3 \mathrm{mg} / \mathrm{kg} /$ day in the second week, and $0 \cdot 15 \mathrm{mg} / \mathrm{kg} / \mathrm{day}$ in the third. Specimens for blood urea and creatinine concentration were collected daily for one week before steroids were started and for as long as five weeks after.

\section{GROUP 4}

In this group of 11 babies, analysis of the urinary $3 \mathrm{MH}$ :creatinine ratio was undertaken in addition to measurement of the blood urea and creatinine, before and after dexamethasone treatment. Urine samples were collected on alternate days for a week before starting steroids and for two weeks after steroids were started.

All babies in group 1,3 , and 4 were in a stable condition before steroids were started and sepsis was excluded throughout by daily $\mathrm{C}$ reactive protein estimations, and blood cultures where appropriate. All were well hydrated with a minimum fluid intake of $165 \mathrm{ml} / \mathrm{kg} /$ day (range $165-200 \mathrm{ml} / \mathrm{kg}$ ), and the fluid intake was not altered during the course of dexamethasone treatment. None of the babies was treated with diuretics and none had evidence of a patent ductus arteriosus.

Urinary nitrogen estimations were performed by the Kjeldahl method, using a Kjeltec Auto 1000 analyser with an analytical coefficient of variation of $<2 \%$ for eight repeat samples. Urea and creatinine estimations were made using a Beckman, Astra 8, Clinical Chemistry Analyser. Urinary $3 \mathrm{MH}$ was measured using a Chromaspek $M$ automated, ion exchange amino acid analyser (Hilger Analytical).

Statistical comparisons between sets of normal data were performed using paired Student's $t$ tests, and between sets of non-normal data by the Mann-Whitney U test.

The study had the approval of the local research (ethics) committee and the parents of the babies.

\section{Results}

GROUP 2

The median gestational and postnatal ages of the 10 babies in group 2 were 33.4 weeks (range $31-35$ ) and $14 \cdot 2$ days (range $7-29$ ) respectively. Fifty urine samples were obtained from the babies in group 2 . The $3 \mathrm{MH}$ :creatinine ratios of these samples were normally distributed about a mean (SD) of $38.3(11.0) \mathrm{mmol} / \mathrm{l}$. The laboratory reproducibility of results had an error of $<5 \%$.

GROUPS 3 AND 4 COMBINED

The babies in groups 3 and 4 were combined for the analysis of the blood urea and creatinine

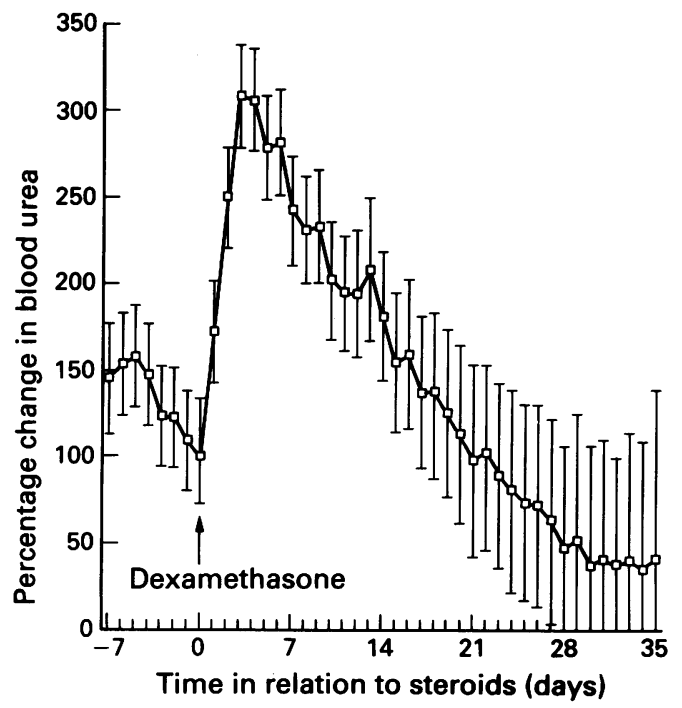

Figure 1 Percentage change in blood urea concentration plotted against time (days) in relation to the start of steroid treatment. Bars show $95 \%$ confidence intervals.

concentrations after dexamethasone. This gave a total of 45 babies. The median gestation for this group was 27 weeks (range: $24-31$ weeks). The median age at the start of steroid treatment was 18 days (range : 7-71 days). The blood urea data are shown in fig 1 . The day before dexamethasone was started the mean (SEM) blood urea was $2 \cdot 3(0 \cdot 28) \mathrm{mmol} / \mathrm{l}$. The concentration then rose to a peak of $7 \cdot 1(0 \cdot 43) \mathrm{mmol} / \mathrm{l}$ on the third day after starting dexamethasone. This was followed by a gradual decline, such that by the end of the three week course the concentration was approximately the same as it had been before treatment.

Figure 2 illustrates the percentage change in the blood creatinine concentration in relation to dexamethasone treatment. It can be seen that the blood creatinine was falling before dexamethasone was started and that trend continued, uninterrupted, after the start of dexamethasone.

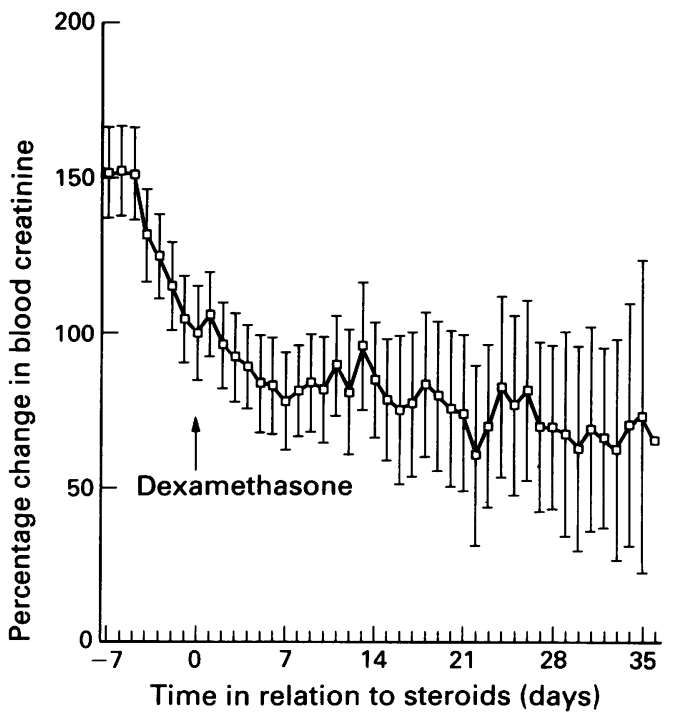

Figure 2 Percentage change in creatinine concentration plotted against time (days) in relation to the start of steroid treatment. Bars show $95 \%$ confidence intervals. 


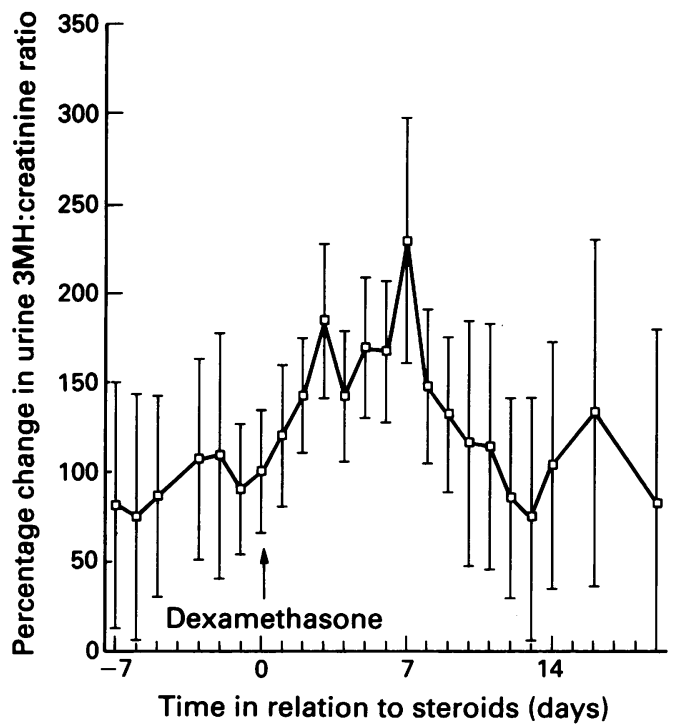

Figure 3 Percentage change in urine $3 M$ H:creatinine ratio plotted against time (days) in relation to the start of steroid treatment. Bars show $95 \%$ confidence intervals.

GROUP 4

The 11 babies in group 4 were very similar to those in group 3. Their median gestational age was 27 weeks (range 24-31) and the median age at which steroids were started was 14 days (range 9-32). The mean blood urea concentration before dexamethasone was started was 2.6 $\mathrm{mmol} / \mathrm{l}$ and this rose to a mean of $6.8 \mathrm{mmol} / \mathrm{l}$ by day 3.

Figure 3 shows the percentage change of urinary $3 \mathrm{MH}$ :creatinine ratio data plotted in relation to dexamethasone treatment. The mean value for the urinary $3 \mathrm{MH}$ :creatinine ratio in the week before starting steroids was 46 and this rose significantly to a mean of 77 in the first week after the start of steroids $(p<0.0001)$. In the next week this ratio fell to a mean of 58 , significantly less than the value in the first week of steroid treatment $(p=0.01)$, but still significantly greater than the pretreatment value $(p=0.03)$. By the third week of steroid treatment the $3 \mathrm{MH}$ :creatinine ratio had fallen to 53 ; this

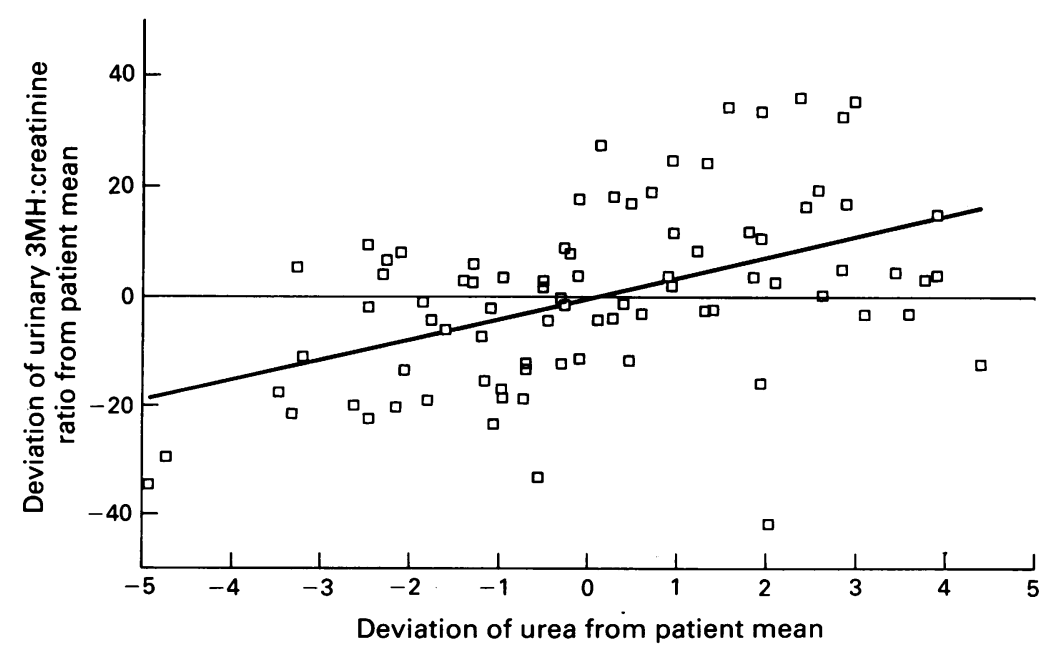

Figure 4 Deviation from patient mean of urine $3 M H$ :creatinine ratio plotted against deviation from patient mean of blood urea concentration. Regression line shown.
Results of nitrogen balance studies. Results are nitrogen retention in $\mathrm{mg} / \mathrm{kg} / 24$ hours

\begin{tabular}{lll}
\hline $\begin{array}{l}\text { Patient } \\
\text { No }\end{array}$ & $\begin{array}{l}\text { Before } \\
\text { steroids }\end{array}$ & $\begin{array}{l}\text { After } \\
\text { steroids }\end{array}$ \\
\hline 1 & 746 & 550 \\
2 & 629 & 560 \\
3 & 611 & 379 \\
4 & 476 & 244 \\
5 & 402 & 242 \\
6 & 386 & 216 \\
7 & 351 & 255 \\
8 & 343 & 298 \\
9 & 338 & 14 \\
10 & 215 & 35 \\
11 & 210 & 176 \\
\hline
\end{tabular}

value was not significantly different from the pretreatment value $(p=0.43)$.

Figure 4 shows the relationship between the urinary $3 \mathrm{MH}$ :creatinine ratio deviation from the patient mean and the blood urea deviation from the patient mean after the start of steroid treatment. There is a significant relationship between the two variables $(r=0.5, p<0.0001)$.

GROUP 1

The 11 babies in group 1 were similar to those in the other groups. The median gestational age was 26 weeks (range 24-31) and the median age at which dexamethasone was started was 19 days (range 8-29).

The results of the nitrogen balance studies are shown in the table. All babies were in positive nitrogen balance before steroids were started and remained so despite steroids. There was, however, a significant reduction in nitrogen retention to approximately half the presteroid value $(\mathrm{p}=0.0006$, paired $t$ test).

\section{Discussion}

This study was conducted in order to investigate the cause of the increase blood urea concentration that we had observed during steroid treatment in preterm babies. Although we suspected the cause to be increased urea production, two other theoretical possibilities had to be considered.

One possibility is that dexamethasone causes a diuresis, which results in contraction of the extracellular fluid volume and consequential rise in blood urea concentration-that is, a dehydration effect. There is evidence of a diuresis after dexamethasone treatment of bronchopulmonary dysplasia. ${ }^{9}$ The workers who described it speculated that the improvement in pulmonary function which dexamethasone produces may relate to the removal of fluid from the lung. However, in order to explain such an increase in the blood urea as we observed the dehydration would have to be severe. The fluid intake throughout our study was substantial (median $180 \mathrm{ml} / \mathrm{kg} /$ day, range 165 to $200 \mathrm{ml} / \mathrm{kg}$ /day), there was no difference in daily urine output collected for the nitrogen balance studies before and during steroid treatment, and there was no clinical evidence of dehydration in any of the babies. There was also no coincidental increase in the serum creatinine, which would be expected with a significant 
degree of dehydration, and the urinary creatinine concentrations did not increase. We are confident, on this evidence alone, to conclude that dehydration was not the explanation for the rise in blood urea which we have documented.

The second possible explanation for a rise in blood urea would be a deterioration in renal function. We see no reason why this should have occurred and found no evidence for it. In particular serum creatinine concentrations did not increase along with the urea concentrations.

The data presented in this paper strongly suggest that the observed increase in blood urea concentration is due almost entirely to an increase in protein catabolism, resulting in the breakdown of structural protein and an increase in urea production. As the preterm baby's capacity to concentrate and excrete urea is relatively poor the result is an accumulation of urea in the blood.

The nitrogen balance data from the babies in group 1 demonstrate beyond doubt that dexamethasone causes increased protein catabolism. The mean deficit in nitrogen retention was $170 \mathrm{mg} / \mathrm{kg} /$ day after the administration of steroids and this is equivalent to $1 \mathrm{~g}$ of protein $/ \mathrm{kg} / \mathrm{day}$. If it is assumed that between $12 \%$ and $14 \%$ of the newborn's weight gain is made up of protein ${ }^{10}$ then $1 \mathrm{~g}$ of protein $/ \mathrm{kg} /$ day represents $7-8 \mathrm{~g} / \mathrm{kg} /$ day of body weight. This would represent half of a newborn's anticipated weight gain.

In group 4 babies we have also shown a significant rise in the urinary $3 \mathrm{MH}$ :creatinine ratio after dexamethasone treatment (fig 3) as well as a significant correlation between blood urea and urine $3 \mathrm{MH}$ :creatinine ratio $(\mathrm{r}=0.611$, $\mathrm{p}<0.0001)$. This shows that the increase in urea production seen with dexamethasone is partly due to increased breakdown of skeletal muscle protein.

It is well established that increased circulating endogenous and exogenous glucocorticoids result in a loss of muscle protein in man and other animals, ${ }^{11}$ and we were not surprised to find that there was a similar effect in the preterm infant. Although to the best of our knowledge, ours is the first primary evidence for this phenomenon which has been produced in the newborn. Dexamethasone is thought to exert its catabolic effect via type 2 corticosteroid receptors, stimulation of which results in an increase in the proportion of fat to lean body mass by reducing protein. ${ }^{12}$

The main concern raised by our data is the possibility that a period of increased catabolism, and therefore interruption of growth, at such a vulnerable time of life might have permanent adverse consequences for growth and development. Catabolism of muscle protein is of course not necessarily detrimental as it can probably be made up for later. It is in any case apparently not too serious for the muscles concerned with breathing as dexamethasone hastens weaning from the ventilator in almost all cases. The real worry is that the catabolic effect of steroids might also adversely affect brain growth, which is less likely to be fully recoverable. The recent work by Lucas et al showing that the quality of nutrition in the early weeks of life may influence later development must be taken very seriously. ${ }^{13}$ The effect of steroids, given in the neonatal period, on neurological outcome has caused concern for some time ${ }^{14}$ and in the experimental animal an adverse effect of steroids on brain growth has been demonstrated. ${ }^{15} 16$ Behavioural changes, delayed maturation, and impairment of fine motor control have been reported in studies on rodents given steroids in the immediate postnatal period. ${ }^{17}$

As with any treatment that has a mixture of good and bad effects the decision to use steroids in a case of bronchopulmonary dysplasia must be on the basis of an appraisal of the risks and benefits as they seem to apply in an individual case. The data in this paper add to the risk side of the equation.

There may be ways to minimise the catabolic effects of corticosteroids. Obvious possibilities would include the use of a smaller dose of dexamethasone, an alternative route of administration, such as nebulisation directly into the lung which would enable smaller doses to be used or the use of different steroid altogether. Another approach might be to try to counteract the catabolic effect with an anabolic hormone such as insulin or an anabolic steroid. However, until fresh approaches are found we would advocate the continued use of dexamethasone in its present dose for cases of severe ventilator dependent bronchopulmonary dysplasia but urge caution in the extension of its use to less severe cases.

1 Greenblatt SH, Long CL, Blakemore WS, Dennis RS, Rayport M, Geiger JW. Catabolic effect of dexamethasone in patients with major head injuries. Fournal of Parenteral and Enteral Nutrition 1986;13:373-6.

2 Ballard FJ, Thomas FM. 3 Methylhistidine as a measure of skeletal muscle protein breakdown in human subjects: the skeletal muscle protein breakdown in human subjects:

3 Hulseman J, Wember T, Kordass U, Sander G, Schmidt E, Schoch G. 3 Methylhistidine/creatinine ratio in urine from Schoch $\mathrm{G}$. 3 Methylhistidine/creatinine ratio in urine from
low birth weight infants. Ann Nutr Metab 1988;32:44-51.

4 Seashore JH, Huszar G, Davis EM. Urinary 3 methylhistidine/ creatinine ratio as a clinical tool: correlation between 3-methylhistidine excretion and metabolic and clinical states in health and stressed premature infants. Metabolism 1981;30:959-69.

5 Gil A, Faus MJ, Robles R, et al. Urinary 3 methylhistidine derivative as indicator of nutrients intake in low birthweight infants. Horm Metab Res 1984;16:667-70.

6 Williamson DH, Farrel R, Kerr A, Smith R. Muscle protein catabolism after injury in man, as measured by urinary excretion of 3-methylhistidine. Clinical Science and Molecular Medicine 1977;52:527-33.

7 Hulsemann J, Kordass U, Sander G, Schmidt E, Schoch G. 3 methylhistidine/creatinine ratio in urine from low birth weight infants. Ann Nutr Metab 1988;32:44-51.

8 Seene TP, Alev KP. Glucocorticoids in intracellular catabolism of myosin and actin. Biull Eksp Biol Med 1986;102:557-9.

9 Gladstone IM, Ehrenkranz RA, Jacobs HC. Pulmonary function tests and fluid balance in neonates with chronic lung disease during dexamethasone treatment. Pediatrics $1989 ; 84: 1072-6$.

10 Fomon SJ. Body composition of the male reference infant during the first year of life. Pediatrics 1967;40:863-70.

11 Goldberg A, Goodman HM. Relationship between cortisone and muscle work in determining muscle size. $\mathcal{f}$ Physiol 1969;200:667-75.

12 Devenport L, Knehans A, Sundstrom A, Thomas T. Corticosterone's dual metabolic actions. Life Sci 1989;45: 1389-96.

13 Lucas A, Morley R, Cole TJ, et al. Early diet in preterm babies and developmental status at 18 months. Lancet 1990;335:1477-81.

14 Fitzhardinge P, Eisen A, Lejtenyi C, Metrakos K, Ramsay $M$. Sequelae of early steroid administration to the newborn infant. Pediatrics 1974;53:877-83.

15 Ohtsu N, Ariagno RL, Sweeny TE, et al. The effect of dexamethasone on chronic pulmonary oxygen toxicity in infant mice. Pediatr Res 1989;25:353-9.

16 Cotterrell M, Balazas R, Johnson A. Effects of corticosteroids on the biochemical maturation of the rat brain. $\mathcal{F}$ Neurochem 1972;19:2151-67.

17 Howard E, Granoff D. Increased voluntary running and decreased motor co-ordination in mice after neonatal corticosterone implantation. Exp Neurol 1968;22:661. 